\title{
A broad exome study of the genetic architecture of asthma reveals novel patient subgroups
}

Sophia Cameron-Christie ${ }^{1}$, Alex Mackay ${ }^{2}$, Quanli Wang ${ }^{1}$, Henric Olsson ${ }^{2}$, Bastian Angermann $^{2}$, Glenda Lassi ${ }^{1,2}$, Julia Lindgren ${ }^{3}$, Michael Hühn², Yoichiro Ohne ${ }^{4}$, Monica Gavala $^{5}$, Jingya Wang ${ }^{5}$, Gundula Povysil ${ }^{6}$, Sri V. V. Deevi ${ }^{1}$, Graham Belfield ${ }^{3}$, Inken Dillmann $^{3}$, Daniel Muthas ${ }^{2}$, Suzanne Cohen ${ }^{7}$, Simon Young $^{8}$, Adam Platt $^{9 *}$, Slavé Petrovski ${ }^{1 *}$

[1] Centre for Genomics Research, Discovery Sciences, BioPharmaceuticals R\&D, AstraZeneca, Cambridge, UK.

[2] Translational Science and Experimental Medicine, Research and Early Development, Respiratory \& Immunology, BioPharmaceuticals R\&D, AstraZeneca, Gothenburg, Sweden.

[3] Translational Genomics, Discovery Sciences, BioPharmaceuticals R\&D, AstraZeneca, Gothenburg, Sweden.

[4] Bioscience Asthma, Research and Early Development, Respiratory \& Immunology, BioPharmaceuticals R\&D, AstraZeneca, Gaithersburg, USA.

[5] Translational Science and Experimental Medicine, Research and Early Development, Respiratory \& Immunology, BioPharmaceuticals R\&D, AstraZeneca, Gaithersburg, USA.

[6] Institute for Genomic Medicine, Columbia University Irving Medical Center, New York, New York.

[7] Bioscience Asthma, Research and Early Development, Respiratory \& Immunology, BioPharmaceuticals R\&D, AstraZeneca, Cambridge, UK.

[8] Respiratory Precision Medicine, Oncology R\&D, AstraZeneca, Cambridge, UK. 
[9] Translational Science and Experimental Medicine, Research and Early Development, Respiratory \& Immunology, BioPharmaceuticals R\&D, AstraZeneca, Cambridge, UK.

*Co-senior authors. These authors contributed equally.

\section{Corresponding author:}

Slavé Petrovski, Centre for Genomics Research, Discovery Sciences, BioPharmaceuticals R\&D, AstraZeneca, Cambridge, UK. Email: slav.petrovski@ astrazeneca.com. Ph: +44 (0) 7384239426

Author contributions: A.P. and S.P. conceived of and designed the study; G.L., S.Y., and A.P., acquired the SAGA clinical trial samples; Q.W., and S.V.V.D performed the bioinformatic processing; J.L., G.B., and I.D. supported sequencing requirements; S.C.C. analyzed the data with support from Q.W., B.A., M.G., D.M., and S.P.; S.C.C., A.M., H.O., B.A., G.L., Y.O., M.G., J.W., D.M., A.P., and S.P. interpreted the data; S.C.C, A.M., A.P. and S.P. drafted the manuscript; and all authors critically revised the manuscript for important intellectual content. 


\section{Abstract}

\section{Introduction}

Asthma risk is a complex interplay between genetic susceptibility and environment. Despite many significantly-associated common variants, the contribution of rarer variants with potentially greater effect sizes has not been as extensively studied. We present an exomebased study adopting 24,576 cases and 120,530 controls to assess the contribution of rare protein-coding variants to the risk of early-onset or all-comer asthma.

\section{Methods}

We performed case-control analyses on three genetic units: variant-, gene- and pathwaylevel, using sequence data from the Scandinavian Asthma Genetic Study and UK Biobank participants with asthma. Cases were defined as all-comer asthma $(n=24,576)$ and early-onset asthma ( $\mathrm{n}=5,962)$. Controls were 120,530 UK Biobank participants without reported history of respiratory illness.

\section{Results}

Variant-level analyses identified statistically significant variants at moderate-to-common allele frequency, including protein-truncating variants in $F L G$ and $I L 33$. Asthma risk was significantly increased not only by individual, common $F L G$ protein-truncating variants, but also among the collection of rare-to-private $F L G$ protein-truncating variants $\left(\mathrm{p}=6.8 \times 10^{-7}\right)$. This signal was driven by early-onset asthma and did not correlate with circulating eosinophil levels. In contrast, a single splice variant in $I L 33$ was significantly protective $\left(\mathrm{p}=8.0 \times 10^{-10}\right)$, while the collection of remaining IL33 protein-truncating variants showed no class effect $(\mathrm{p}=0.54)$. A pathway-based analysis identified that protein-truncating variants in loss-offunction intolerant genes were significantly enriched among individuals with asthma. 


\section{Conclusions}

Access to the full allele frequency spectrum of protein-coding variants provides additional clarity about the potential mechanisms of action for FLG and IL33. Beyond these two significant drivers, we detected a significant enrichment of protein-truncating variants in lossof-function intolerant genes. 


\section{Introduction}

Asthma is the $10^{\text {th }}$ highest cause of Disability Adjusted Life Years (DALYs) worldwide[1], affecting >300 million adults[2]. Though geographic prevalence varies[2,3], asthma remains the most common chronic condition in children[3]. With prevalence rising over time[3,4] the global burden of asthma provides a significant public health challenge. Despite the recent emergence of effective therapies, predominantly targeting elevated type 2 inflammation[5], only four novel therapy mechanisms have been FDA approved since 2000[6]. This leaves many individuals living with asthma that is poorly controlled and treated stochastically, on symptomatology rather than underlying pathobiology[7]. To successfully develop novel therapeutics, a 'precision medicine' approach is vital to target treatments to patient populations most likely to benefit[8].

Twin studies estimate asthma heritability at $35 \%$ in adults $[9,10]$ and $80 \%$ in children[11,12], suggesting genetics plays a major part in disease development, particularly in early-onset asthma. Over the last two decades, the primary tool for identifying genetic asthma factors was microarray-based, genome wide association studies (GWAS). These identified and replicated dozens of common single nucleotide polymorphisms and multi-gene loci correlated to asthma risk, including the 6p21 HLA region, 17q12-21 (ORMDL3, GSDML and IKZF3)[13], and individual genes such as IL33[14]. Most observed odds ratios for asthma GWAS are <1.1, occasionally as high as 2 (EBI GWAS Catalogue[15]).

The contribution of rare variants to asthma risk has not been thoroughly studied. Despite numerous, pedigree-based studies of familial asthma[16,17], the only variants reported in ClinVar[18] or the Online Mendelian Inheritance in Man (OMIM[19]) are two relatively common protein-truncating variants in the gene filaggrin $(F L G)$, each with a minor allele 
frequency (MAF) of 1-2\% in West-European populations[20], associated with allergic phenotypes and childhood asthma[21]. To overcome a lack of power with individual rare variants, gene-unit methods such as collapsing analysis[22,23] have identified known and novel disease-associated genes.

We present the first comprehensive, exome-wide sequence analysis of a large asthma population. Our study focuses on the genetic architecture of asthma by investigating the contribution of protein-coding variation across three genomic test units: 1) variant-level, exome-wide association study (exWAS), 2) gene-based collapsing analysis, and 3) pathwaybased burden analysis. We applied these methods to $>24,000$ participants with asthma from the UK Biobank (UKB) and an AstraZeneca clinical trial, compared to exomes from more than 120,000 participants of the UKB without asthma or respiratory conditions (Figure 1). Additionally, given the high heritability of childhood asthma[11,12] early-onset cases may carry more high-risk variants, so we also extended our analyses to the early-onset $(<18$ years old) asthma sub-group.

\section{Methods}

\section{Clinical cohorts}

The Scandinavian Asthma Genetic Study (SAGA) is an AstraZeneca clinical trial that ran between 1999 and 2000. Participants were recruited from 10 centres spanning Denmark, Norway and Sweden. The original study involved 532 families, of which at least two children had a clinical diagnosis of asthma (Section S1), totalling 2,392 participants. Genomes of 422 index subjects from distinct families were sequenced. 
The UK Biobank is a project which recruited circa 500,000 adults aged 40-69 years in 20062010 from 22 centres across Britain. Participants provided DNA, biomarkers, past and ongoing medical records, and underwent further health assessments and monitoring. This resource is available to approved researchers for health-related research in the public interest (www.ukbiobank.ac.uk).

\section{Ethics}

Ethics committees at all recruiting institutions approved the SAGA study, which was performed in accordance with the provisions of the Declaration of Helsinki as defined by the International Conference on Harmonization, Good Clinical Practice, and applicable regulatory requirements, and the policy on bioethics and human biologic samples of the trial sponsor, AstraZeneca. During the study, participants or guardians provided consent for the collection and use of DNA and clinical data for genetic research related to asthma and/or asthma-related conditions.

Ethical approval for the UK Biobank (UKB) was granted by the UK National Health Service National Research Ethics Service (Research Ethics Committee approval number 11/NW/0382). Participants provided consent for general research consistent with the UK Biobank stated purpose, to improve the prevention, diagnosis, and treatment of illness and the promotion of health throughout society.

\section{Case Selection}

Two groups of cases were defined: 'all asthma' and 'early asthma' for cases diagnosed at <18 years of age. 
SAGA families were of North-West-European ancestry. Median age at diagnosis was three years for cases. UKB cases were selected if they had an ICD diagnosis of asthma

(Supplementary Material S1) or if they self-reported a diagnosis of asthma (Field ID 20002, code 1111). Age of UKB self-reported asthma diagnoses were 0-76 years, median 33.5 (Figure S1).

After quality filtering (Table S1), the all-comer asthma group comprised of 415 SAGA and 24,161 UKB participants with an asthma diagnoses. For the 'early asthma' group, UKB subjects were included with self-reported diagnosis at $<18$ years of age (UKB $n=5552$ and SAGA $n=410)$.

\section{Control Selection}

Control subjects were selected from the UKB if they lacked a self-reported or ICD10 diagnosis of asthma, or any other major respiratory illness (Table S1), and their UKB records reported an FEV1/FVC>70\%. From 200,603 participants with exome sequence data, this totalled 120,530 UKB controls.

\section{Sequencing and Bioinformatics}

Genomic DNA from UKB participants underwent paired-end 75bp whole exome sequencing (WES) at Regeneron Pharmaceuticals using IDT xGen v1 capture kit and NovaSeq6000.

SAGA subjects were extracted and underwent paired-end 150bp WGS at Human Longevity Inc using the NovaSeq6000 platform. For all UKB participants, >95\% of CCDS had at least 10x coverage and average coverage of CCDS was 59X. For both cases and controls, alignment to GRCh38 and SNV and indel calling were performed using a custom-built Amazon Web Services (AWS) cloud compute platform running Illumina DRAGEN Bio-IT 
Platform Germline Pipeline v3.0.7. SNVs and indels were annotated using SnpEFF v4.3 against Ensembl Build 38.92 (Section S2).[24] SNVs and indels with MAPQ<30 were excluded from all analyses. Demographic checks of sex and predicted ancestry were performed (Section S2).

\section{Subject Quality Control (QC)}

Exomes were excluded if they didn't qualify a set of subject-level QC, including contamination levels, discordance between reported and genetic-predicted sex, low coverage of the target exome boundaries, and read-depth outliers (Table S1). Due to the available data, this study focused on subjects of European genetic ancestry (Table S1).

exWAS (variant level)

We performed an exome-wide association study (exWAS) across all protein-coding variants seen $\geq 8$ times in the combined case-control cohort. We studied four genetic modes of inheritance: allelic, genotypic, dominant and recessive.

\section{Collapsing Analysis (gene level)}

In collapsing analysis, we aggregate variants fitting a given set of criteria within each gene, identified as 'qualifying variants' (QVs).[22] We performed 11 non-synonymous collapsing analyses, 10 dominant and one recessive model, plus an additional synonymous variant model as a negative control. In each model, for each gene, the proportion of cases is compared to the proportion of controls carrying one or more qualifying variants in that gene, except the recessive model, where a subject must have two qualifying alleles. The criteria for 
qualifying variants in each collapsing analysis model are in Table S3, all with identical QC filters (Table S2).

MegaGene (gene-set) Analysis

We applied MegaGene[25] to investigate biologically relevant gene-sets and pathways enriched for genes with qualifying variants in the case or control groups. We tested 9,341 pre-defined gene-sets for each genetic model (Supplementary material S3). Briefly, we applied a logistic regression model comparing disease status to the number of genes containing qualifying variants (qualifying genes, QGs), with three covariates: sex, number of synonymous QVs per individual per gene set (accounting for differences in neutral variation rate between gene sets), and the exome-wide tally of QVs an individual has in the tested model.

\section{Statistics}

Calculations performed in R software (version 3.6.2).[26] For exWAS, we defined significance as the conventional $\mathrm{p}<5 \times 10^{-08}$. For collapsing analysis, we used a two-sided Fisher's exact test for P-values with a conservative, Bonferroni, study-wide significance threshold as $\mathrm{p}<2.6 \times 10^{-7}(0.05 /[(18695$ genes $) *(10$ non-synonymous models $)])$. Because genesets have considerable overlap, we focus on gene-sets achieving Benjamini \& Hochberg (FDR) adjusted $\mathrm{p}<0.01$. 


\section{Results}

Gene-based collapsing analyses identified a number of highly-ranked genes of potential interest (Table 1 and S4, Figure S3), including study-wide significant results for FLG and near-significance for IL33. ExWAS analyses identified 45 variants associated with asthma risk in known loci (Table S5). Finally, gene-set analysis identified a previously unreported case enrichment of PTVs in loss-of-function intolerant genes (Figure 4, Table S6).

\section{FLG loss-of-function variants significantly increase risk of childhood asthma}

In gene-based collapsing analysis of PTVs with MAF $<5 \%$ we observed a study-wide significant association between FLG PTVs (OMIM\#135940) in early-onset ( $\mathrm{p}=5.2 \times 10^{-41}$, $\mathrm{OR}=1.64,95 \% \mathrm{CI} 1.53-1.75)$, and all asthma $\left(\mathrm{p}=2.3 \times 10^{-18}, \mathrm{OR}=1.20,95 \% \mathrm{CI} 1.15-1.25\right)$,

Figure 2; Table 2). Beyond the two well-known common FLG PTVs, we observed an additional 269 distinct FLG PTVs in our cohort; 115 (43\%) were private, seen in only a single subject. The two most common $F L G$ variants (MAF>1\%)[21,27], rs61816761-G-A and rs558269137-CACTG-C, are observed among $10.6 \%$ of all cases. The remaining variants observed, each at less than $1 \%$ MAF, accounted for the remaining 3.4\% of cases. In total, 3,368/24,567 cases carry at least one putative truncating variant in FLG (13.7\%). When we restricted the PTV collapsing analysis in $F L G$ to a MAF $<1 \%$, the collection of rare $F L G$ PTVs remained highly significant, with a consistent odds ratio to common PTVs (p-value $6.8 \times 10^{-7}, \mathrm{OR}=1.22,95 \% \mathrm{CI}=1.13-1.32$ ) providing firm evidence that $F L G$ PTVs as a class increase asthma risk.

To further examine the reported relationship between FLG PTV carriers and asthma, we stratified the UK Biobank self-declared participants into groups with asthma onset of $<10$ years, 10-18 years, or $\geq 18$ years. The strongest effect of carrying a FLG PTV was on the 
youngest asthma group $\left(\mathrm{p}=8.5 \times 10^{-37}, \mathrm{OR}=1.82,95 \% \mathrm{CI} 1.67-1.99\right)$, with a moderate effect at 10-18 years old $\left(\mathrm{p}=1.9 \times 10^{-7}, \mathrm{OR}=1.38,95 \% \mathrm{CI} 1.22-1.55\right)$, and no measurable effect on the rate of asthma in adults $(\mathrm{p}=0.9, \mathrm{OR}=1.00,95 \% \mathrm{CI}$ 0.95-1.06) (Table 2).

The effect of recessive FLG loss, in homozygous or likely compound heterozygous PTV carriers, is even stronger (Table 3, Figure 3). Biallelic carriers of FLG PTVs have over a 9fold increase in asthma diagnosed before 10 years old $\left(\mathrm{p}=1.0 \times 10^{-53}, \mathrm{OR}=9.2,95 \% \mathrm{CI} 7.27\right.$ 11.56), a 3.5-fold increase of diagnoses between $10-18$ years $\left(\mathrm{p}=2.3 \times 10^{-7}, \mathrm{OR}=3.5,95 \% \mathrm{CI}\right.$ 2.25-5.30), and over 1.5-fold increase of adult diagnoses $\left(\mathrm{p}=2.7 \times 10^{-5}, \mathrm{OR}=1.77,95 \% \mathrm{CI} 1.36\right.$ 2.27).

Because common FLG PTVs have been associated with increased allergy phenotypes[27], most studies investigating $F L G$ and asthma posit that $F L G$ perturbation and skin barrier dysfunction leads to an increase in allergy risk, resulting in allergic asthma risk. Consistent with this, asthma patients with a FLG PTV were more likely to self-report, or be diagnosed, with an allergic phenotype compared to $F L G$ carriers with no asthma $\left(\mathrm{p}=1.5 \times 10^{-143} \mathrm{OR}=3.58\right.$, 95\%CI 3.26-3.94). However, when excluding UK Biobank participants who had eczema, atopic dermatitis, psoriasis, or allergic rhinitis, among other phenotypes (Supplementary material S1) the relationship between FLG PTV carrier status and early-onset asthma remained significant $\left(<18\right.$ y.o., $\left.\mathrm{p}=3.4 \times 10^{-14}, \mathrm{OR}=1.42,95 \% \mathrm{CI} 1.30-1.55\right)$.

\section{A protective IL-33 variant is less prevalent in early-onset asthma}

A previously reported asthma-associated gene, IL33, (OMIM\#608678) was depleted of PTVs among all asthma cases in the UK Biobank $\left(\mathrm{p}=8.7 \times 10^{-7}, \mathrm{OR}=0.69,95 \% \mathrm{CI}=0.60-0.81\right)$, with greater depletion in early-onset asthma $\left(\mathrm{p}=4.9 \times 10^{-4}, \mathrm{OR}=0.59,95 \% \mathrm{CI}=0.43-0.80\right)($ Figure 3,

Table 4). Closer review of the underlying data determined the signal was driven by a single 
splice variant found at a MAF of $0.36 \%$ among non-Finnish Europeans[28] $\left(\mathrm{p}=8.0 \times 10^{-10}\right.$, $\mathrm{OR}=0.58,95 \% \mathrm{CI}: 0.48-0.70)$. This replicates findings from a previous report[24] that the IL33 rs146597587-C splice variant is depleted among individuals with asthma. That study[24] demonstrated a loss-of function phenotype when one rs146597587-C allele was present. Compared to controls, we observed that IL33 rs146597587-C carrier rates were significantly lower in early-onset (<18 y.o.) asthmatics compared to later onset $(0.39 \%$ carriers in early vs. $0.61 \%$ in late onset, Fisher's exact $\mathrm{p}=0.001$ ). Both groups are lower than controls $(0.88 \%)$.

In our cohort we identified an additional 380 individuals carrying one of 13 rare IL33 PTVs (highest MAF=0.13\%). Notably, unlike the class effect in FLG variants, the remaining IL33 PTVs do not achieve a significant relationship with asthma status $(\mathrm{p}=0.54, \mathrm{OR}=1.09$, 95\%CI=0.83-1.41) (Table 4).

Relationship between asthma risk variants and eosinophil counts

To determine whether the carrier status of FLG PTVs, carriers of IL33 splice-site rs 146597587-C, or carriers of other IL33 PTVs have a relationship with blood eosinophil counts, we examined the UKB, European participants with both exome sequence data and eosinophil levels available ( $\mathrm{n}=144,570)$. We applied rank-based inverse normal transformation to normalise the eosinophil count distribution (UKB Field 30150, instance 0). After correcting for recruitment age and sex in linear regression, we confirmed previous reports[24] that the 1,184 carriers of the rs146597587-C IL33 splice variant had significantly lower eosinophil counts than the 143,386 non-carriers, irrespective of disease status $\left(p=2.3 \times 10^{-23} ; \beta=-0.29\right.$, standard error=0.03), but no significant relationship was observed with eosinophil counts among 380 carriers of other IL33 PTVs $(p=0.10 ; \beta=-0.08$, standard 
error=0.05), and no relationship among 17,374 carriers of FLG PTVs $(\mathrm{p}=0.13 ; \beta=-0.01$, standard error $=0.01)$.

\section{Variant Analysis}

In the all-comer asthma group, 45 variants achieved $\mathrm{p}<5 \times 10^{-8}$ (Table S5). Thirty-two (70\%) were inside the 6p21 HLA-associated locus and six (13\%) were in the previously implicated 17p21 locus[13]. The remaining eight loci (19\%), which include the two most common FLG PTVs, have all been previously reported in association with asthma, with the exception of a variant in $R P T N$, which appears to be in linkage with a FLG PTV. No protein-coding variants in the nearby $17 \mathrm{p} 12$ locus, also linked to asthma[13], achieved $\mathrm{p}<1 \times 10^{-6}$. In the early asthma group, the 40 significant variants were already identified as significant in the all-asthma group, but $32(80 \%)$ reported higher odds ratios in early asthma (Table S6), consistent with previous reports[21].

\section{MegaGene analysis}

Two gene-sets achieved FDR-adjusted p<0.01 (Figure 4 and S4, Table S7.1). The topranked gene-set was observed in the PTV collapsing analysis model, in all asthma, reflecting genes intolerant to loss-of-function mutations in human populations, according to the gnomAD pLI score[28] ( $\mathrm{pLI}>0.9, \mathrm{n}=3230$ genes, FDR $\left.\mathrm{p}=4.1 \times 10^{-5}\right)$. The second-ranked geneset is drawn from the same pLI gene-set but excludes pLI genes previously reported in OMIM ( $\mathrm{pLI}>0.9, \mathrm{n}=2275$ genes, FDR $\mathrm{p}=0.0005$ ). Only 148 genes from the latter gene-set achieved $\mathrm{p}<0.1$ in the original collapsing analysis (Table S7.2). Both gene-sets were also similarly enriched in the early asthma group, though not significantly. 


\section{Discussion}

This work demonstrates the value of exome sequencing to gain insight into the genetic architecture of asthma, even among known genes. Within $F L G$, two well-described PTVs (rs558269137-CACTG-C NP_002007.1:p.Ser761fs and rs61816761-G-A

NP_002007.1:p.Arg501Ter) have each independently risen to relatively common frequencies (MAF 1\%) in global populations[28]. In our data, comprising of sequences from 24,576 subjects with asthma, $>12 \%$ of West Europeans carry at least one FLG PTV, including hundreds of rare-to-private PTVs. Exome sequence data allowed us to further catalogue the full allelic spectrum of genetic variation in $F L G$ and establish with high confidence that the effect of rare and ultra-rare FLG PTVs is comparable to the two common FLG PTVs. Moreover, by comparing FLG PTV asthma risk across age groups, we show that FLG PTVs are most relevant to childhood-onset asthma, with no evidence of an increase in adult-onset asthma in heterozygotes. Further, we confirmed that this increased risk is significant and substantial in those who otherwise report no allergy phenotype. Finally, we observed that the FLG PTV genetic model appears to be additive, whereby recessive FLG PTV genotypes carry a significantly greater risk of developing asthma compared to single FLG PTV carriers.

Common noncoding (presumed regulatory) variants mapped to IL33 have been previously linked to an increase in $I L 33$ expression and asthma risk[15]. In contrast to $F L G$, where we observed a PTV class effect, in IL33 the protective PTV signal currently appears specific to a single, previously reported, essential splice variant[15] (GRCh38 chr9:g.6255967G>C, rs 146597587-C)[24]. We observed a significant decrease in eosinophil count in carriers of this splice variant, but no significant association with eosinophils among the collection of 
remaining IL33 PTVs. The absence of a similar protective signal among these rarer IL33 PTVs is puzzling, since rs 146597587 was functionally characterised as a loss-of-function variant[24], and two clinically efficacious IL33-depleting therapies were recently reported[29]'[30].

Our exWAS analysis replicated known asthma associations across 44 variants in 33 coding genes (Figure S2). Although our exWAS did not observe significant associations with variants in $O R M D L 3, I L 1 R L 1$, or GSDMB, three genes commonly linked to asthma in microarray GWAS, the exWAS only examines the contribution of protein-coding variants, suggesting these previously reported signals might be driven by noncoding regulatory aberrations rather than linkage to protein-coding variation.

Interestingly, in the MegaGene analysis, we observed an enrichment of PTVs occurring in genes that are intolerant to truncating mutations in humans, which was significant in the all asthma cohort, and similar but non-significant in the early-asthma group. It is particularly notable that we observed the significant enrichment only in PTVs and not in other categories of variants. This finding remains something to validate in future studies.

Although asthma is recognised as a heterogenous disease, current stratification of relevant subgroups is limited mainly to Type 2 (T2) inflammation driven disease. Our analysis of two previously recognised risk loci indicates possible genetic identification of further patient subgroups. The lack of association of FLG PTVs with eosinophil count, often used as a surrogate biomarker for $\mathrm{T} 2$ inflammation, suggests they act potentially independently and may overlap both $\mathrm{T} 2$ and non-T2 driven patients. Furthermore, we found that $F L G$ is a risk factor of only childhood asthma, and the IL-33 protective loss-of-function variant is linked to a larger IL-33 drive in early onset asthma. This indicates potential new biomarkers of 
etiological subgroups, and a precision medicine approach may enable the selection of patients with an IL-33 drive may identify a IL-33 inhibitor responsive asthma sub-population.

This study is, to our knowledge, the largest to attempt a comprehensive search for rare, highrisk variants or genes in asthma. We demonstrate how access to the full allele frequency spectrum via sequencing provides clarity on the underlying contribution to disease risk for previously implicated genes. For other common complex conditions in which the risk contribution of rare variation is unknown, sequencing can help illuminate the genetic architecture. With the advent of large biobanks with comprehensive phenotyping, such as the UKB, such studies will be increasingly possible for a wider range of conditions. 


\section{Acknowledgements}

During this work, SCC was supported by the AstraZeneca postdoc program. We would like to thank David B Goldstein from Columbia University Medical Centre for his valuable feedback during the early stages of this research study. We would like to thank all participants and organisers of the UK Biobank for creating an open scientific resource for the research community. This work was referring UKB application 26041. We would also like to thank the investigators involved in the SAGA study, and all participants of the original SAGA study.

\section{Financial Support}

This study was sponsored by BioPharmaceuticals R\&D, AstraZeneca, Cambridge, UK.

AstraZeneca funded sequencing, infrastructure and salaries of authors and was involved in collection. 
Tables

Table 1. Top 20 gene results from non-synonymous collapsing analysis, ranked by lowest $p$-value

\begin{tabular}{|c|c|c|c|c|c|c|c|c|c|c|}
\hline Group & Model & $\begin{array}{c}\mathbf{n} \\
\text { cases }\end{array}$ & $\begin{array}{l}\text { Gene } \\
\text { Name }\end{array}$ & $\begin{array}{l}\text { Qual } \\
\text { Case } \\
\text { Freq }\end{array}$ & $\begin{array}{c}\text { Qual } \\
\text { Ctrl } \\
\text { Freq }\end{array}$ & $\begin{array}{l}\text { Enriched } \\
\text { Direction }\end{array}$ & FET P & $\begin{array}{l}\text { Odds } \\
\text { Ratio }\end{array}$ & $\begin{array}{c}\text { Odds } \\
\text { Ratio } \\
\text { LCI }\end{array}$ & $\begin{array}{c}\text { Odds } \\
\text { Ratio } \\
\text { UCl }\end{array}$ \\
\hline early asthma & PTVcommon & 5962 & $F L G$ & $0 \cdot 1780$ & $0 \cdot 1168$ & Case & $5 \cdot 2 \times 10^{-41}$ & 1.64 & 1.53 & $1 \cdot 75$ \\
\hline all asthma & PTVcommon & 24579 & $F L G$ & $0 \cdot 1370$ & $0 \cdot 1168$ & Case & $2 \cdot 3 \times 10^{-18}$ & $1 \cdot 20$ & $1 \cdot 15$ & $1 \cdot 25$ \\
\hline all asthma & PTVcommon & 24579 & IL33 & 0.0079 & 0.0114 & Control & $8.7 \times 10^{-7}$ & 0.69 & 0.60 & 0.81 \\
\hline early asthma & flexnonsyn & 5962 & CAMK1D & 0.0050 & 0.0018 & Case & $3.6 \times 10^{-6}$ & $2 \cdot 74$ & $1 \cdot 87$ & $4 \cdot 02$ \\
\hline early asthma & $\mathrm{rec}$ & 5962 & CA12 & 0.0008 & $1 \cdot 7 \mathrm{E}-5$ & Case & $4.5 \times 10^{-6}$ & $50 \cdot 58$ & $9 \cdot 81$ & $260 \cdot 78$ \\
\hline early asthma & $\mathrm{rec}$ & 5962 & PALM3 & 0.0007 & 0.0000 & Case & $4.9 \times 10^{-6}$ & $\operatorname{Inf}$ & NA & NA \\
\hline all asthma & raredmgmtr & 24579 & RELB & 0.0007 & 0.0001 & Case & $5 \cdot 2 \times 10^{-6}$ & 4.91 & $2 \cdot 55$ & $9 \cdot 43$ \\
\hline early asthma & flexnonsynmtr & 5962 & CAMK1D & 0.0042 & 0.0014 & Case & $6.7 \times 10^{-6}$ & $2 \cdot 96$ & 1.95 & $4 \cdot 51$ \\
\hline early asthma & $\mathrm{rec}$ & 5962 & ASCC3 & 0.0017 & 0.0002 & Case & $7 \cdot 5 \times 10^{-6}$ & $7 \cdot 23$ & $3 \cdot 51$ & $14 \cdot 89$ \\
\hline early asthma & raredmg & 5962 & TGFB1 & $0 \cdot 0040$ & 0.0014 & Case & $1.1 \times 10^{-5}$ & $2 \cdot 95$ & 1.92 & $4 \cdot 53$ \\
\hline early asthma & flexnonsyn & 5962 & MRGPRX3 & 0.0099 & 0.0052 & Case & $1 \cdot 1 \times 10^{-5}$ & 1.92 & 1.47 & $2 \cdot 51$ \\
\hline all asthma & flexnonsyn & 24579 & CAMK1D & 0.0033 & 0.0018 & Case & $1.1 \times 10^{-5}$ & $1 \cdot 81$ & 1.41 & $2 \cdot 34$ \\
\hline all asthma & raredmg & 24579 & CNGB1 & 0.0037 & 0.0059 & Control & $1.3 \times 10^{-5}$ & 0.63 & 0.50 & $0 \cdot 78$ \\
\hline all asthma & raredmg & 24579 & TEDDM1 & 0.0000 & 0.0005 & Control & $2 \cdot 1 \times 10^{-5}$ & $\operatorname{lnf}$ & NA & NA \\
\hline all asthma & ptv & 24579 & ACTRT3 & $0 \cdot 0004$ & $4 \cdot 2 \mathrm{E}-5$ & Case & $2.5 \times 10^{-5}$ & $9 \cdot 81$ & $3 \cdot 35$ & $28 \cdot 71$ \\
\hline all asthma & PTVcommon & 24579 & ACTRT3 & 0.0004 & $4 \cdot 2 \mathrm{E}-5$ & Case & $2.5 \times 10^{-5}$ & $9 \cdot 81$ & $3 \cdot 35$ & $28 \cdot 71$ \\
\hline all asthma & flexnonsynmtr & 24579 & CAMK1D & 0.0027 & 0.0014 & Case & $2.7 \times 10^{-5}$ & 1.90 & 1.43 & $2 \cdot 52$ \\
\hline early asthma & flexnonsyn & 5962 & SH3BP5 & 0.001 & 0.004 & Control & $3.9 \times 10^{-5}$ & 0.25 & $0 \cdot 11$ & 0.56 \\
\hline early asthma & flexdmg & 5962 & SH3BP5 & 0 & 0.0018 & Control & $4.2 \times 10^{-5}$ & 0 & NA & NA \\
\hline early_asthma & raredmgmtr & 5962 & SLC35A4 & 0.002 & 0.00044 & Case & $4.6 \times 10^{-5}$ & $4 \cdot 58$ & $2 \cdot 45$ & 8.58 \\
\hline
\end{tabular}

FET = Fisher's Exact Test, $\mathbf{L C I} / \mathbf{U C I}=$ Lower/Upper Confidence Interval (95\%). Model parameters are shown in Table S3.

Table 2. Effect of FLG PTV variants on asthma risk

\begin{tabular}{|c|c|c|c|c|c|c|c|c|}
\hline $\begin{array}{c}\text { Subject } \\
\text { Group }\end{array}$ & n cases & PTV criteria & $\begin{array}{c}\text { Qual } \\
\text { Case } \\
\text { Freq }\end{array}$ & $\begin{array}{c}\text { Qual Ctrl } \\
\text { Freq }\end{array}$ & FET P & $\begin{array}{c}\text { Odds } \\
\text { Ratio }\end{array}$ & $\begin{array}{c}\text { OR } \\
\text { (Lower } \\
95 \% \text { CI) }\end{array}$ & $\begin{array}{c}\text { OR } \\
\text { (Upper } \\
95 \% \text { CI }\end{array}$ \\
\hline All asthma & 24576 & MAF $\geq 1 \%$ & $13 \cdot 7 \%$ & $11 \cdot 7 \%$ & $2 \cdot 3 \times 10^{-18}$ & 1.20 & 1.15 & 1.25 \\
\hline All asthma & 24576 & $<1 \%$ MAF & $3.45 \%$ & $2.9 \%$ & $6 \cdot 8 \times 10^{-07}$ & 1.22 & 1.13 & 1.32 \\
\hline $\begin{array}{c}\text { Early-onset } \\
\text { asthma }\end{array}$ & 5962 & All & $18 \%$ & $12 \%$ & $5 \cdot 2 \times 10^{-41}$ & 1.64 & 1.53 & 1.75 \\
\hline $\begin{array}{c}\text { Adult-onset } \\
\text { asthma } \\
(\geq 18)\end{array}$ & 12974 & All & $11.7 \%$ & $11.7 \%$ & 0.90 & 1.00 & 0.95 & 1.06 \\
\hline
\end{tabular}

FET = Fisher's Exact Test, $\mathbf{P T V}=$ protein truncating mutation, $\mathbf{M A F}=$ minor allele frequency, $\mathbf{C l}=$ Confidence Interval (95\%). 
Table 3. Effect of FLG PTV variants in self-reported UKB asthma cases diagnosed at $<10$ years old $(\mathrm{n}=3342)$. 'Recessive' includes homozygotes and putative compound heterozygotes.

\begin{tabular}{|c|c|c|c|c|c|c|c|}
\hline $\begin{array}{l}\text { Variant } \\
\text { criteria }\end{array}$ & Variant ID & $\begin{array}{l}\text { Qual } \\
\text { case } \\
\text { freq } \\
(\%)\end{array}$ & $\begin{array}{l}\text { Qual ctrl } \\
\text { freq }(\%)\end{array}$ & FET P & $\begin{array}{l}\text { Odds } \\
\text { ratio }\end{array}$ & $\begin{array}{l}\text { Lower } \\
\text { CI 95\% }\end{array}$ & $\begin{array}{l}\text { Upper } \\
\text { CI } 95 \%\end{array}$ \\
\hline \multirow{3}{*}{ All } & rs61816761-G-A & $8 \cdot 26$ & $4 \cdot 47$ & $6.9 \times 10^{-21}$ & $1 \cdot 9$ & $1 \cdot 7$ & $2 \cdot 2$ \\
\hline & $\begin{array}{c}\text { rs558269137- } \\
\text { CACTG-C }\end{array}$ & $8 \cdot 32$ & $4 \cdot 57$ & $4.0 \times 10^{-20}$ & $1 \cdot 9$ & $1 \cdot 7$ & $2 \cdot 1$ \\
\hline & rare variants $<1 \%$ & $4 \cdot 88$ & $2 \cdot 85$ & $2 \cdot 7 \times 10^{-10}$ & $1 \cdot 7$ & $1 \cdot 5$ & $2 \cdot 1$ \\
\hline Recessive & $\begin{array}{l}\text { homozygous or } \\
\text { carrying two } \\
\text { distinct PTVs }\end{array}$ & $2 \cdot 90$ & $0 \cdot 32$ & $1.0 \times 10^{-53}$ & $9 \cdot 2$ & $7 \cdot 3$ & $11 \cdot 6$ \\
\hline
\end{tabular}

FET = Fisher's Exact Test, $\mathbf{P T V}=$ protein truncating mutation, $\mathbf{C l}=$ Confidence Interval (95\%).

Table 4. Effect of IL33 PTV variants on asthma risk

\begin{tabular}{|c|c|c|c|c|c|c|c|c|}
\hline $\begin{array}{l}\text { Subject } \\
\text { Group }\end{array}$ & $\mathrm{n}$ cases & PTV Criteria & $\begin{array}{l}\text { Qual } \\
\text { Case } \\
\text { Freq }\end{array}$ & $\begin{array}{l}\text { Qual } \\
\text { Ctrl } \\
\text { Freq }\end{array}$ & FET P & $\begin{array}{l}\text { Odds } \\
\text { Ratio }\end{array}$ & $\begin{array}{c}\text { OR } \\
\text { (Lower } \\
95 \% \text { CI) }\end{array}$ & $\begin{array}{c}\text { OR } \\
\text { (Upper } \\
95 \% \mathrm{CI} \text { ) }\end{array}$ \\
\hline All asthma & 24576 & All $(\mathrm{AF}<5 \%)$ & $0.79 \%$ & $1 \cdot 1 \%$ & $8 \cdot 7 \times 10^{-7}$ & 0.69 & 0.60 & $0 \cdot 81$ \\
\hline All asthma & 24576 & $\mid \begin{array}{c}\text { Excluding } \\
\text { rs146597587-C }\end{array}$ & $0 \cdot 28 \%$ & $0 \cdot 26 \%$ & $0 \cdot 54$ & $1 \cdot 09$ & $0 \cdot 83$ & $1 \cdot 41$ \\
\hline All asthma & 24576 & $\begin{array}{c}\text { Only } \\
\text { rs146597587-C }\end{array}$ & $0 \cdot 51 \%$ & $0 \cdot 88 \%$ & $7 \cdot 4 \times 10^{-10}$ & 0.58 & 0.48 & $0 \cdot 70$ \\
\hline $\begin{array}{c}\text { Early-onset } \\
\text { asthma }\end{array}$ & 5962 & All $(\mathrm{AF}<5 \%)$ & $0 \cdot 67 \%$ & $1 \cdot 1 \%$ & $4.9 \times 10^{-4}$ & 0.59 & 0.43 & $0 \cdot 80$ \\
\hline $\begin{array}{l}\text { Early-onset } \\
\text { asthma }\end{array}$ & 5962 & $\begin{array}{c}\text { Only } \\
\text { rs146597587-C }\end{array}$ & $0 \cdot 39 \%$ & $0 \cdot 88 \%$ & $1 \cdot 0 \times 10^{-5}$ & 0.44 & $0 \cdot 27$ & 0.66 \\
\hline $\begin{array}{l}\text { Adult-onset } \\
\text { asthma } \\
\quad(\geq 18)\end{array}$ & 12974 & $\begin{array}{c}\text { Only } \\
\text { rs146597587-C }\end{array}$ & $0.61 \%$ & $0.88 \%$ & 0.001 & 0.69 & 0.54 & 0.87 \\
\hline
\end{tabular}

FET = Fisher's Exact Test, $\mathbf{P T V}=$ protein truncating mutation, $\mathbf{C l}=$ Confidence Interval (95\%). 


\section{Figure Legends}

Figure 1. Case and control cohorts.

Figure 2. Collapsing analysis of genes in all-comer asthma shows that synonymous variants (negative control) matched the expected distribution of $\mathrm{p}$-values while among the minor allele frequency (MAF) $<5 \%$ protein truncating variant (PTV) collapsing model, cases are significantly enriched for PTVs in FLG. (A) synonymous variants, (B) PTV only, MAF<5\% filter

Figure 3. Distribution of age at asthma diagnosis in UK BioBank for (A) All FLG protein truncating variant (PTV) variant carriers (n=2511, red), versus FLG PTV non-carriers $\left(\mathrm{n}=16,015\right.$, blue), $\mathrm{P}=1.90 \times 10^{-21}$. (B) Recessive $F L G$ PTV carriers $(\mathrm{n}=196$, red) versus $F L G$ PTV non-carriers $(\mathrm{n}=16,015$, blue $), \mathrm{P}=7.9 \times 10^{-28}$. (C) Age at diagnosis for carriers of the IL33 rs 146597587-C protective splice-site variant $(n=99$, red), versus homozygous reference cases with no IL33 PTVs (n=18,376, blue), P=0.001. (D) Case carriers of an alternative IL33 PTV other than rs146597587-C ( $\mathrm{n}=51$, red) versus non-carriers $(\mathrm{n}=18,376$, blue), $\mathrm{P}=0.46$.

Figure 4. Quantile-quantile plots show the distribution of gene sets in the MegaGene analysis using variants classed as (A) rare synonymous variants or (B) rare protein-truncating variants and all asthma cases. 


\section{References}

1. Organization WH. The global burden of disease: 2004 update. 2008.

2. To T, Stanojevic S, Moores G, Gershon AS, Bateman ED, Cruz AA, Boulet L-P. Global asthma prevalence in adults: findings from the cross-sectional world health survey. BMC Public Health 2012: 12(1): 204.

3. Asher I, Pearce N. Global burden of asthma among children. The International Journal of Tuberculosis and Lung Disease 2014: 18(11): 1269-1278.

4. Masoli M, Fabian D, Holt S, Beasley R, Program GIfA. The global burden of asthma: executive summary of the GINA Dissemination Committee report. Allergy 2004: 59(5): 469-478.

5. Global Initiative for Asthma. Global Strategy for Asthma Management and Prevention. Date last updated: June 2019 [cited Date last accessed: March 2020]; Available from: www.ginasthma.org 6. US Food and Drug Administration. Novel drug approvals for 2017-2019. Date last updated: 01/10/2020 [cited Date last accessed: March 2020]; Available from: Available from:

https://www.fda.gov/drugs/development-approval-process-drugs/new-drugs-fda-cders-newmolecular-entities-and-new-therapeutic-biological-products

7. Pavord ID, Beasley R, Agusti A, Anderson GP, Bel E, Brusselle G, Cullinan P, Custovic A, Ducharme FM, Fahy JV, Frey U, Gibson P, Heaney LG, Holt PG, Humbert M, Lloyd CM, Marks G, Martinez FD, Sly PD, von Mutius E, Wenzel S, Zar HJ, Bush A. After asthma: redefining airways diseases. Lancet 2018: 391(10118): 350-400.

8. Dugger SA, Platt A, Goldstein DB. Drug development in the era of precision medicine. Nature Reviews Drug Discovery 2018: 17(3): 183-196.

9. Nieminen MM, Kaprio J, Koskenvuo M. A Population-based Study of Bronchial Asthma in Adult Twin Pairs. Chest 1991: 100(1): 70-75.

10. Thomsen SF, Duffy DL, Kyvik KO, Backer V. Genetic influence on the age at onset of asthma: A twin study. Journal of Allergy and Clinical Immunology 2010: 126(3): 626-630.

11. Ullemar V, Magnusson PKE, Lundholm C, Zettergren A, Melén E, Lichtenstein P, Almqvist C. Heritability and confirmation of genetic association studies for childhood asthma in twins. Allergy 2016: 71(2): 230-238.

12. Laitinen T, Räsänen M, Kaprio J, Koskenvuo M, Laitinen LA. Importance of Genetic Factors in Adolescent Asthma. American Journal of Respiratory and Critical Care Medicine 1998: 157(4): 10731078.

13. Stein MM, Thompson EE, Schoettler N, Helling BA, Magnaye KM, Stanhope C, Igartua C, Morin A, Washington C, Nicolae D, Bønnelykke K, Ober C. A decade of research on the 17q12-21 asthma locus: Piecing together the puzzle. Journal of Allergy and Clinical Immunology 2018: 142(3): 749-764.e743.

14. Ferreira MA, McRae AF, Medland SE, Nyholt DR, Gordon SD, Wright MJ, Henders AK, Madden PA, Visscher PM, Wray NR, Heath AC, Montgomery GW, Duffy DL, Martin NG. Association between ORMDL3, IL1RL1 and a deletion on chromosome 17q21 with asthma risk in Australia. Eur J Hum Genet 2011: 19(4): 458-464.

15. Buniello A, MacArthur JA L, Cerezo M, Harris LW, Hayhurst J, Malangone C, McMahon A, Morales J, Mountjoy E, Sollis E, Suveges D, Vrousgou O, Whetzel PL, Amode R, Guillen JA, Riat HS, Trevanion SJ, Hall P, Junkins H, Flicek P, Burdett T, Hindorff LA, Cunningham F, Parkinson H. The NHGRI-EBI GWAS Catalog of published genome-wide association studies, targeted arrays and summary statistics 2019. Nucleic Acids Research 2018: 47(D1): D1005-D1012.

16. Postma DS, Bleecker ER, Amelung PJ, Holroyd KJ, Xu J, Panhuysen CIM, Meyers DA, Levitt RC. Genetic Susceptibility to Asthma - Bronchial Hyperresponsiveness Coinherited with a Major Gene for Atopy. New England Journal of Medicine 1995: 333(14): 894-900.

17. Hakonarson H, Bjornsdottir US, Halapi E, Palsson S, Adalsteinsdottir E, Gislason D, Finnbogason G, Gislason T, Kristjansson K, Arnason T, Birkisson I, Frigge ML, Kong A, Gulcher JR, 
Stefansson K. A Major Susceptibility Gene for Asthma Maps to Chromosome 14q24. The American Journal of Human Genetics 2002: 71(3): 483-491.

18. Landrum MJ, Lee JM, Benson M, Brown G, Chao C, Chitipiralla S, Gu B, Hart J, Hoffman D, Hoover J, Jang W, Katz K, Ovetsky M, Riley G, Sethi A, Tully R, Villamarin-Salomon R, Rubinstein W, Maglott DR. ClinVar: public archive of interpretations of clinically relevant variants. Nucleic Acids Res 2016: 44(D1): D862-868.

19. McKusick-Nathans Institute of Genetic Medicine JHUB, MD),. Online Mendelian Inheritance in Man, $\mathrm{OMIM}^{\circledR}$. [cited 2020-02-01]; Available from: https://omim.org/

20. Sherry ST, Ward M-H, Kholodov M, Baker J, Phan L, Smigielski EM, Sirotkin K. dbSNP: the NCBI database of genetic variation. Nucleic acids research 2001: 29(1): 308-311.

21. Pividori M, Schoettler N, Nicolae DL, Ober C, Im HK. Shared and distinct genetic risk factors for childhood-onset and adult-onset asthma: genome-wide and transcriptome-wide studies. The Lancet Respiratory Medicine 2019: 7(6): 509-522.

22. Petrovski S, Todd JL, Durheim MT, Wang Q, Chien JW, Kelly FL, Frankel C, Mebane CM, Ren Z, Bridgers J. An Exome Sequencing Study to Assess the Role of Rare Genetic Variation in Pulmonary Fibrosis. American journal of respiratory and critical care medicine 2017(ja).

23. Zhu X, Padmanabhan R, Copeland B, Bridgers J, Ren Z, Kamalakaran S, O'Driscoll-Collins A, Berkovic SF, Scheffer IE, Poduri A, Mei D, Guerrini R, Lowenstein DH, Allen AS, Heinzen EL, Goldstein DB. A case-control collapsing analysis identifies epilepsy genes implicated in trio sequencing studies focused on de novo mutations. PLOS Genetics 2017: 13(11): e1007104.

24. Smith D, Helgason $H$, Sulem $P$, Bjornsdottir US, Lim AC, Sveinbjornsson $G$, Hasegawa $H$, Brown M, Ketchem RR, Gavala M, Garrett L, Jonasdottir A, Jonasdottir A, Sigurdsson A, Magnusson OT, Eyjolfsson GI, Olafsson I, Onundarson PT, Sigurdardottir O, Gislason D, Gislason T, Ludviksson BR, Ludviksdottir D, Boezen HM, Heinzmann A, Krueger M, Porsbjerg C, Ahluwalia TS, Waage J, Backer V, Deichmann KA, Koppelman GH, Bønnelykke K, Bisgaard H, Masson G, Thorsteinsdottir U, Gudbjartsson DF, Johnston JA, Jonsdottir I, Stefansson K. A rare IL33 loss-of-function mutation reduces blood eosinophil counts and protects from asthma. PLOS Genetics 2017: 13(3): e1006659.

25. Petrovski S. MegaGene analysis. 2018 [cited; Available from:

https://github.com/astrazeneca-cgr-publications

26. R Core Team. R: A language and environment for statistical computing. 2014.

27. Irvine AD, McLean WHI, Leung DYM. Filaggrin Mutations Associated with Skin and Allergic Diseases. New England Journal of Medicine 2011: 365(14): 1315-1327.

28. Karczewski KJ, Francioli LC, Tiao G, Cummings BB, Alföldi J, Wang Q, Collins RL, Laricchia KM, Ganna A, Birnbaum DP, Gauthier LD, Brand H, Solomonson M, Watts NA, Rhodes D, Singer-Berk M, England EM, Seaby EG, Kosmicki JA, Walters RK, Tashman K, Farjoun Y, Banks E, Poterba T, Wang A, Seed C, Whiffin N, Chong JX, Samocha KE, Pierce-Hoffman E, Zappala Z, O'Donnell-Luria AH, Minikel EV, Weisburd B, Lek M, Ware JS, Vittal C, Armean IM, Bergelson L, Cibulskis K, Connolly KM, Covarrubias M, Donnelly S, Ferriera S, Gabriel S, Gentry J, Gupta N, Jeandet T, Kaplan D, Llanwarne C, Munshi R, Novod S, Petrillo N, Roazen D, Ruano-Rubio V, Saltzman A, Schleicher M, Soto J, Tibbetts K, Tolonen C, Wade G, Talkowski ME, Neale BM, Daly MJ, MacArthur DG. Variation across 141,456 human exomes and genomes reveals the spectrum of loss-of-function intolerance across human protein-coding genes. bioRxiv 2019: 531210 .

29. Londei M, Marquette-Hamoudi A, Phenis K, Pinkstaff J, Sacco N, Pavord I. Single-dose Phase 2a trial of etokimab (anti-IL-33) in severe eosinophilic asthma. In: ALLERGY; 2019: WILEY 111 RIVER ST, HOBOKEN 07030-5774, NJ USA; 2019. p. 128-128.

30. Regeneron Pharmaceuticals Inc. 'Regeneron and Sanofi Announce Positive Topline Phase 2 Results for IL-33 Antibody in Asthma'. 2019 [cited 15/04/2020]; Available from:

https://www.prnewswire.com/news-releases/regeneron-and-sanofi-announce-positive-toplinephase-2-results-for-il-33-antibody-in-asthma-300872459.html 


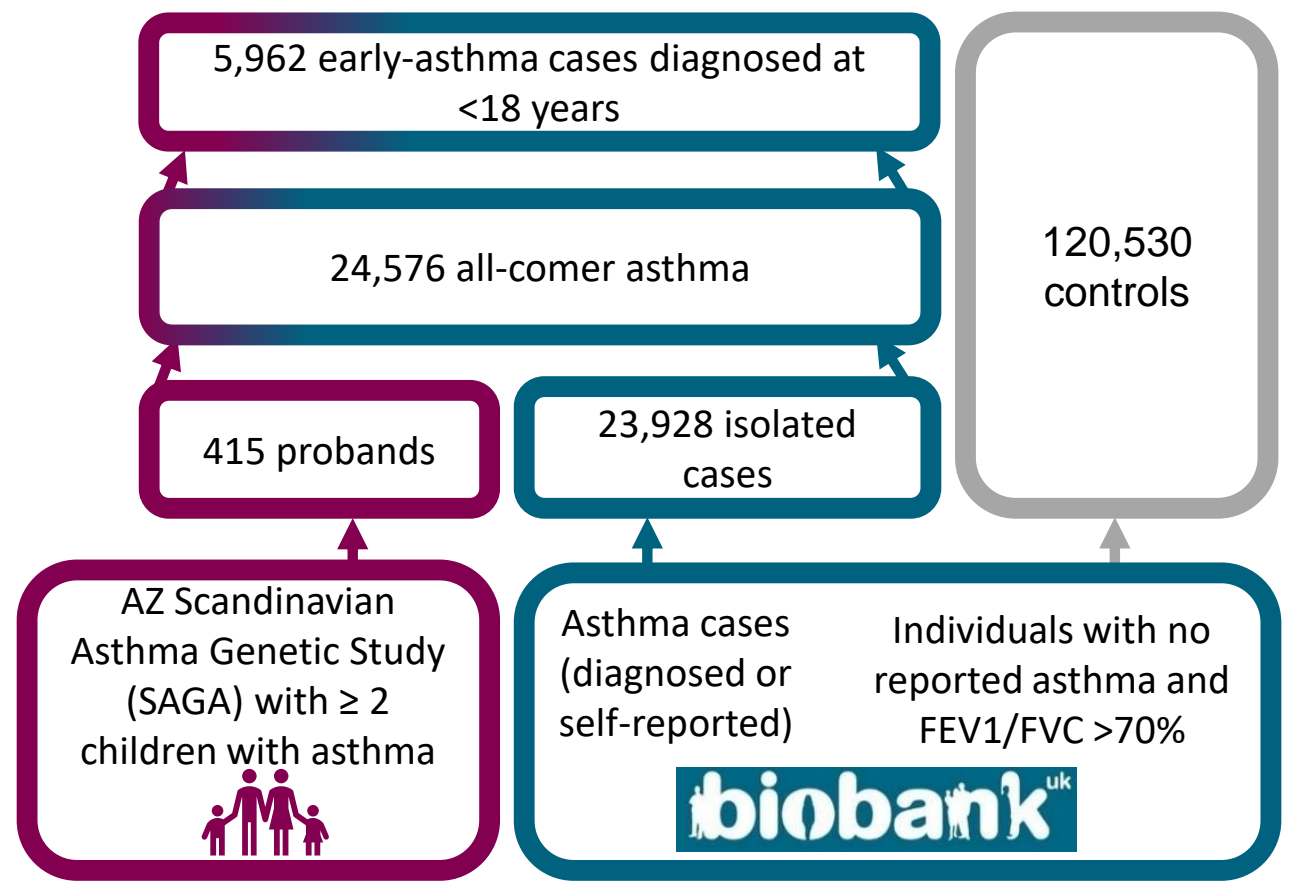


a)

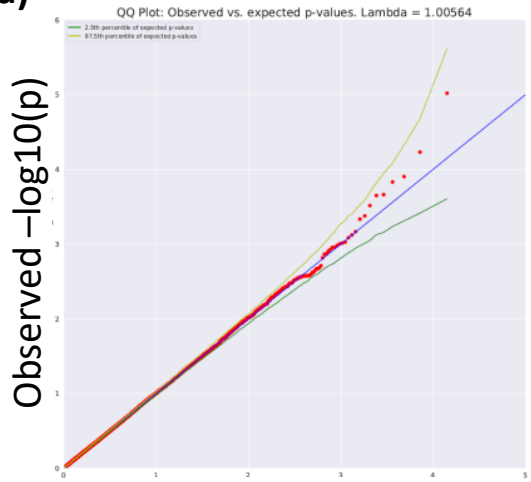

Expected $-\log 10(p)$ b)

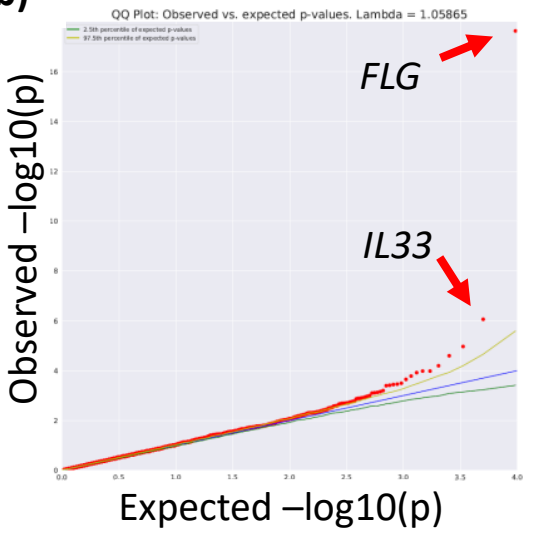




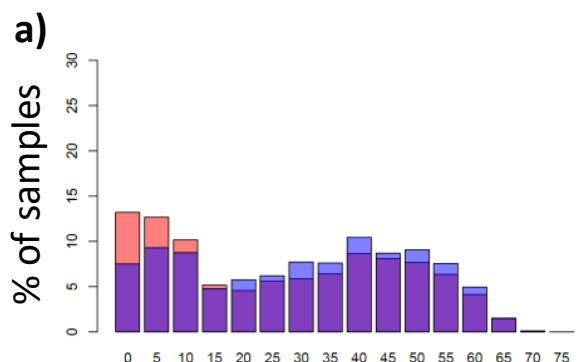

c) subject diagnosis age

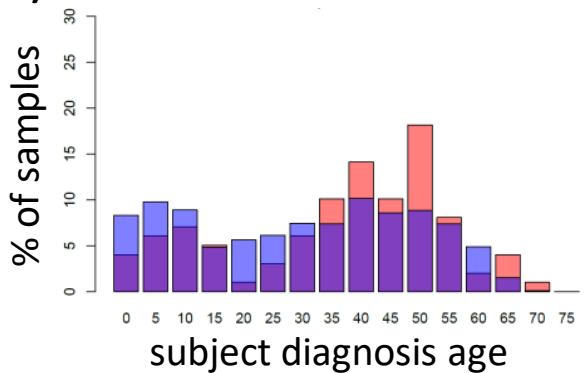

b)

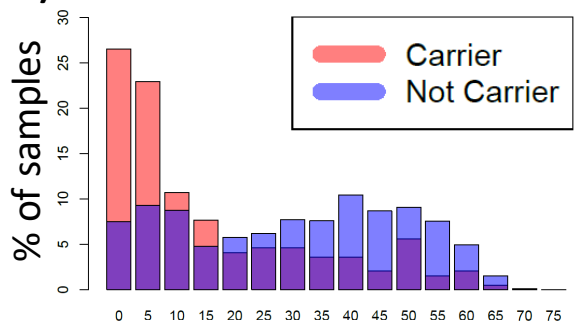

d) subject diagnosis age

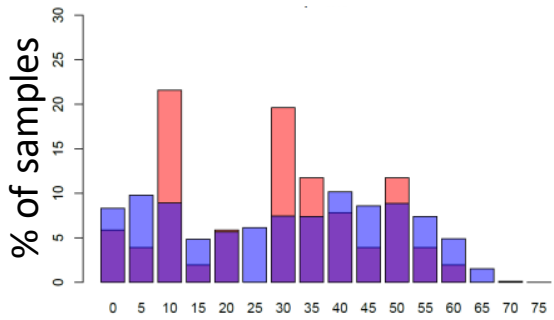
subject diagnosis age 
a) all asthma Synonymous

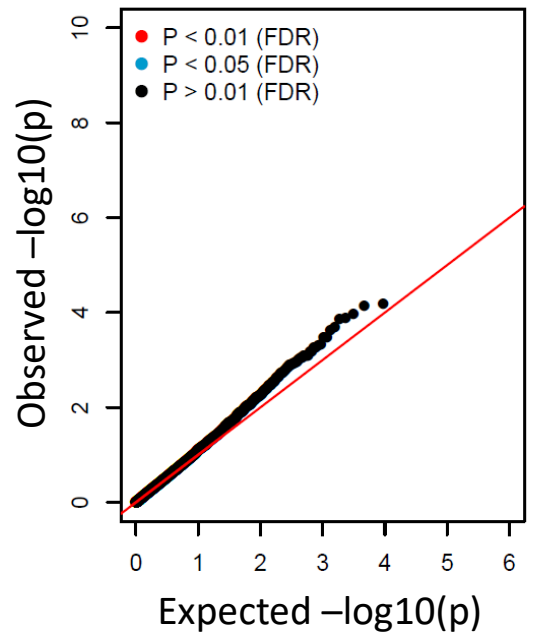

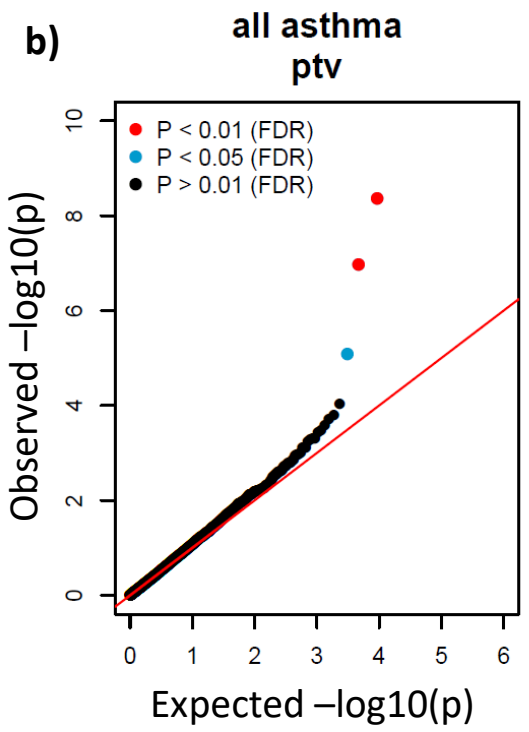

